abilities and 31 (3\%) had major congenital malformations. In a few instances (nine) the history of a relative was uncertain or could not be verified, and they were removed from the calculations.

There were two sisters with a similar nonprogressive ataxic disorder whose histories and computed tomograms could have been consistent with Joubert's syndrome, and one boy whose mother had a similar condition.

\section{Discussion}

The prevalence of neurodevelopmental disability in a general population similar to the one reported here and using similar criteria, has been reported to be $12-16 \% .5$ An increased frequency of neurodevelopmental disability in the direct families and near relatives of those with ataxic cerebral palsy could thus not be shown. The figure of $8 \%$ is somewhat low, and this may have been due to underascertainment as, although a thorough history was taken and parents were asked to contact their relatives, a disability may not have been admitted. However, about 100 cases would have to be missed to achieve an $18 \%$ incidence of neurodevelopmental disability and it is most unlikely that those numbers were missed. It would have been more satisfactory if the frequency of neurodevelopmental disability in the local population had been known.

The figures for 1980-3 for the percentage of Western Australian births with a major congenital malformation ranges from $3 \cdot 2 \%$ to $4 \cdot 2 \%$ (Western Australian Congenital Malformations Register Annual Report, 1984), a similar figure to that found in the current study.

Ingram, ${ }^{6}$ in his study of ataxic cerebral palsy, reported a high proportion of near relatives with different types of neurological disorder, and Mon- real in a clinic population study of cerebral palsied children stated that there was an unusual number of relatives with cerebral palsy, mental retardation, and seizures. ${ }^{2}$ The methods used in those two studies differ, however, from those used in this report, and the results are not really comparable.

This study of a large proportion of a metropolitan population of patients with ataxic cerebral palsy does not support a genetic non-Mendelian influence in the aetiology of this heterogeneous disorder.

I am indebted to Dr Fiona Stanley and Linda Watson for access to the West Australian cerebral palsy register, the Spastics Welfare Association of Western Australia, and to Carolyn Ebell for preparation of the manuscript.

\section{References}

${ }^{1}$ Stanley FJ. Prenatal risk factors in the study of the cerebral palsies. In: Stanley FJ, Alberman E, eds. The epidemiology of the cerebral palsies. Clinics in developmental medicine No 87. Spastics International Medical Publications. Oxford: Blackwell Scientific Publications Ltd, 1984: 87-97.

2 Monreal FJ. Considerations of genetic factors in cerebral palsy. Dev Med Child Neurol 1985;27:325-30.

3 Hagberg B, Hagberg G, Olow I. The changing panorama of cerebral palsy in Sweden. 1954-1970. II. Analysis of various syndromes. Acta Paediatr Scand 1975;64:193-200.

4 Bax M. Terminology and classification of cerebral palsy. Dev Med Child Neurol 1964;6:295-7.

5 Drillien C, Drummond M. Developmental screening and the child with special needs. A population study of 5000 children. Clinics in developmental medicine No 86. Spastics International Medical Publications. London: William Heinemann Medical Books Ltd, 1983:55-89.

${ }^{6}$ Ingram TTS. Congenital ataxic syndromes in cerebral palsy. Acta Paediatr Scand 1962;51:209-21.

Correspondence and address for reprints to Dr G Miller, Department of Pediatrics, Division of Neurology, Milton S Hershey Medical Center, Pennsylvania State University, PO Box 850, Hershey, PA 17033, USA.

Accepted 3 February 1988

\title{
Have school entry medicals had their day?
}

\author{
F D KENNEDY
}

Carnmoney Health Centre, Newtownabbey, Northern Ireland

SUMMARY Examination of the school health records of 1033 primary school entrants showed that there was a high level of preschool surveillance by health visitors and that most problems recorded at school entry medical examinations were already known to another professional.
It is policy in Northern Ireland that all children commencing primary school are given a school entry medical examination. There are widely differing views held about the value of these routine examinations. Some believe they are of little value ${ }^{1}$ while others consider them to be of special importance. ${ }^{2}$ The aims of this study were firstly to determine the number of children with records of preschool 
surveillance by health visitors and secondly to determine the number and types of problems found at the school entry medical examination and how these were dealt with.

\section{Methods}

The study population included children who in September 1986 commenced ordinary primary schools in the health care district of Newtownabbey. The district has a population of 72000 (of which 14000 are schoolchildren) and is a largely urban community close to Belfast.

When a child starts school the health visitor records should be transferred to the school health service. At the school entry medical examination each child has a general physical examination by the school doctor and height, weight, and visual acuity measured by the school nurse. Neurodevelopmental screening tests are not routinely carried out in Newtownabbey. In some parts of the district the local speech therapist visits primary schools and sees children at their parent's or teacher's request. Hearing is screened by the educational audiology service. The school health record for each child should therefore consist of the health visitor records and notes made at the school entry medical examination.

The children who started at primary school were identified from the school rolls. Their school health records were retrospectively examined to ascertain the availability of health visitor records, recorded contacts by the health visitor since the child was aged 3 , whether a school entry medical examination was done during the school year September 1986June 1987, the nature of problems detected at the examination, and how these were dealt with (dental problems excluded). A problem was considered 'new' if it was found for the first time or, had been previously known but had recurred. A problem was considered 'already known' if another health professional was dealing with it. New problems that were referred were followed up by contacting the relevant health professional and ascertaining what action had been taken. (The exception to this was in the case of referrals to an optician when parents were contacted about the outcome.)

\section{Results}

Of the 1048 children in the study population, 12 were excluded as they had moved out of the district therefore their records had been transferred. The records of three children could not be traced; this left 1033 school health records in the study.

The health visitor records were available for 951 children $(92 \%)$. The records showed that 899 children had been seen by a health visitor since 3 years of age of whom $858(83 \%$ of 1033$)$ had a developmental check recorded (usually in the form of a standard questionnaire). In most cases hearing and vision were not formally tested by health visitors.

Of the 1033 children, $985(95 \%)$ had a school entry medical examination. A total of 613 problems were recorded in 457 children (that is, $46 \%$ of the children seen had at least one problem); 382 problems $(62 \%)$ were already known to another professional; 231 (38\%) were new. Of the 231 new problems almost half (115) did not require referral, the remaining 116 were referred to another professional. Details of the types of problems and referral patterns are shown in table 1.

The six commonest new problems are shown in table 2 . They represent $83 \%$ of all the new problems found. It is apparent that had children been screened for only four problems (vision/squint, speech, hearing, and short stature) $69 \%$ of detected new problems would have been found.

Of the 116 new problems that were referred, 90

Table 1 Types of problems and referral patterns in 457 children

\begin{tabular}{lcccc}
\hline Type of problem & $\begin{array}{l}\text { Total } \\
\text { No }(\%)\end{array}$ & $\begin{array}{l}\text { No of } \\
\text { already known } \\
\text { problems }\end{array}$ & $\begin{array}{l}\text { No of } \\
\text { new problems }\end{array}$ & $\begin{array}{l}\text { No of } \\
\text { new problems } \\
\text { referred }\end{array}$ \\
\hline Physical* & $304(50)$ & 224 & 80 & 45 \\
Vision/squint & $116(19)$ & 38 & 78 & 49 \\
Hearing & $93(15)$ & 64 & 29 & 13 \\
Speech & $75(12)$ & 45 & 40 & 1 \\
Behaviour & $14(2)$ & 4 & 2 & 0 \\
Learning difficulty & $6(1)$ & 3 & 2 & 2 \\
Social & $5(<1)$ & 231 & 116 \\
\hline Total & 613 & 382 & & \\
\hline
\end{tabular}

${ }^{*}$ Physical problems other than vision, hearing, speech. 
Table 2 Commonest new problems

\begin{tabular}{ll}
\hline Type of new problem & $\begin{array}{l}\text { No of } \\
\text { new problems }\end{array}$ \\
\hline Vision/squint & 78 \\
Speech & 30 \\
Hearing & 29 \\
Short stature & 22 \\
Cardiovascular & 17 \\
Undescended testes & 16 \\
\hline Total & 192 \\
\hline
\end{tabular}

(78\%) referral appointments were kept. Vision, hearing, and speech problems accounted for well over half $(59 \%)$ of new problems referred. Of those seen at referral, 51 problems $(57 \%)$ required some sort of intervention.

\section{Discussion}

The results of this study show a high level of preschool surveillance by health visitors in the district. Although $46 \%$ of the children seen for a school entry medical examination were recorded to have a problem, $62 \%$ of these problems were already known to another professional. Other studies also report low yields of new problems. ${ }^{3}{ }^{4}$ In this study most new problems could have been found by screening tests that need not involve a doctor. This suggests that medical time would be better spent on selected children. It has been shown that parents like their children to have school medical examinations-parental opposition to a selective policy might therefore be anticipated. ${ }^{5} \mathrm{~A}$ practicable solution would be for the school nurse to screen children and refer those she feels require further assessment to the school doctor. This would allow more time for comprehensive assessments of selected children. As many school doctors also work in community child health clinics more time could be given to preschool surveillance work.

Other alternatives to routine school entry medical examinations have been put forward. ${ }^{36}$ Any new system will require evaluation before it can be proved to be better than the present one. It does seem, however, that little is being achieved by unselective medicals and that a change is long overdue.

I thank those who cooperated in this study particularly the general practitioners, also my senior colleagues who gave constructive advice in the preparation of this paper.

The results of this study were presented at Part 2 of the course for Community Health Doctors at the Royal Institute of Public Health and Hygiene, Portland Place, London, in October 1987.

\section{References}

1 Oberklaid F. The ritual school health examination: an idea whose time has passed? Aust Paediatr J 1985;21:155-7.

2 Whitmore K, Bax M. The school entry medical examination. Arch Dis Child 1986;61:807-17.

3 Lunn J. School health service work in the ordinary day schools: 11. A modified selective inspection procedure derived from a study of the periodic entrance inspection. The Medical Officer 1967;118:313-5.

${ }^{4}$ Reznik R, Starte D, Morey S. Health screening at school entry-what is achieved? Aust Paediatr J 1985;21:159-62.

5 Lucas S. Some aspects of child health care: contacts between children, general prctitioners and school doctors. Community Med 1980;2:209-18.

6 O'Callaghan E, Colver A. Selective medical examinations on starting school. Arch Dis Child 1987;62:1041-3.

Correspondence to Dr F Kennedy, 11 Tobermore Road, Magherafelt BT45 5HB, Northern Ireland.

Accepted 16 June 1988 